- mine near Cleveland, Ohio, to search for proton decay. The so-called IMB (Irvine-Michigan-Brookhaven) collaboration shared in the detection of a burst of neutrinos from supernova SN1987A, which strongly corroborated existing theories of the dynamics of stellar collapse.

While Reines

and Cowan knew

what they were

looking for, Perl's

discovery of the tau

lepton was completely unexpected.

"We started out

trying to under-

stand the relation-

ship of the electron

and the muon, but Reines: continuing the we just didn't make search for neutrinos.

any progress," says

Perl. "Finally we started to wonder if maybe there were more leptons; maybe there were a lot of them."

The discovery of the tau was made possible by the construction at the Stanford Linear Accelerator Center (SLAC) of a new accelerator called SPEAR, which Perl and colleagues began using in 1973. In the experiments, electrons and positrons collided at unprecedented energies, giving rise to a plethora of secondary particles.

Painstaking analysis was required to extract the signature of the tau from the raw data. "Our apparatus was primitive and incomplete, and we weren't very good at distinguishing leptons from pions," says Perl. Evidence for the new particle emerged within a couple of years, but Perl says that he and Gary Feldman, now professor of physics at Harvard University, "agonized over the data" before their findings were corroborated by other experiments.

Kurt Gottfried, of Cornell University, admits that when Perl said he had evidence that could only be explained by a new charged lepton, "people were very scepti$\frac{1}{4}$ cal". But he says of Perl and Reines: "These are very
IMAGE

UNAVAILABLE FOR

COPYRIGHT

REASONS excellent choices".

Sidney Drell, a colleague of Perl's for more than 30 years at SLAC, describes the award to Perl as a "superb choice"; the experi-

Perl: lepton discoverer ments were "brilliis 'one of a kind'. antly conceived and executed". Perl, he says, is "one of a kind", who likes to experiment off the beaten track.

Perl is currently attempting to detect free quarks. So far, the existence of quarks has been inferred from experiments on composite objects such as the proton. "Some people think this experiment is a waste of time," he says. "But a few have suggested that there may be free quarks left over as relics from the early universe".

Mark Buchanan

\title{
French research centres told to make their patents pay
}

\& Paris. Elisabeth Dufourcq, France's secretary of state for research, has criticized public research organizations for not doing enough to patent their research results, holding up the aggressive patenting policies of the Atomic Energy Commission (CEA) as an example to follow.

In a bid to encourage researchers to place greater emphasis on patenting, Dufourcq said last week that the government is planning to submit legislation to the National Assembly during its 1995-96 session. This would include giving research teams onequarter of the royalties arising from patents on their work, she said, adding that no ceiling would be imposed on such earnings.

"To submit a patent is to prepare the future, to plant a flag on a new land," said Dufourcq, who was speaking during a visit of the CEA's research centre at Saclay, near Paris. The CEA itself holds almost 1,400 patents, around 900 of which are derived from non-nuclear research. Last year the agency filed 158 patents, and its portfolio earned a substantial income.

In contrast, the patent portfolio of the Centre National de la Recherche Scientifique (CNRS) cost the agency as much as FF125 million in maintenance fees over the past decade. This situation, which critics have attributed in part to CNRS giving too large a share of royalties to licensees, has prompted the agency to review its policy on patenting and to prune back its

\section{Japan accelerates synchrotron plans}

Tokyo. The world's most powerful synchrotron, Japan's SPring-8, is to be commissioned a year ahead of schedule, thanks to an extra $¥ 14.9$ billion (US\$149 million) allocated to the project in a recent special supplementary budget designed to boost the flagging Japanese economy.

Project administrators at the Institute for Physical and Chemical Research (RIKEN), of the Science and Technology Agency (STA), claim that the accelerated schedule has been welcomed by the 900 or so Japanese researchers already recruited into the user's group to carry out experiments on the first 10 beam lines, now due to take place in late 1997. But they admit that the new schedule will make it difficult to recruit the foreign researchers needed to form a large international users' group in time for the commissioning of the $8-\mathrm{GeV}$ synchrotron.

SPring-8 is being built by RIKEN in cooperation with the Japan Atomic Energy Research Institute (JAERI) and the ring will be administered by the Japan Synchro- collection (see Nature 358; 531; 1992).

But the impact of the proposed measures is difficult to predict, particularly because the research organizations already provide individual researchers with a negotiated share of royalties on patents. It is also unclear, for example, whether the government intends to regulate the share of royalties demanded by research organizations from companies licensing their patents.

One senior official from the national biomedical research organization, INSERM, also contests the proposal that there should be no ceiling on researchers' earnings from royalties. Indeed, INSERM has been considering introducing just such a ceiling, he says, as it considers it unfair that some researchers should earn much more than others. The issue of such discrepancies is all the more sensitive, he adds, because INSERM's statutes forbid it to pay bonuses to staff who volunteer for administrative and other duties.

At the Institut Pasteur, whose income from patents tripled between 1988 and 1994, rising from 9 to 18 per cent of its FF860 million budget (see Nature 371, 277; 1994), researchers are not allowed to earn more than FF300,000 annually from royalties. Although the institute is a private organization, it hosts many CNRS and INSERM laboratories, and will need to review its policies when the decree is promulgated, says an official.

Declan Butler

tron Radiation Research Institute (JASRI). User fees have yet to be decided, but a JASRI spokesman says use of the facility's beamlines will essentially be "free".

SPring-8 will eventually incorporate 61 beamlines, in addition to a 1-GeV linac and an 8-GeV synchrotron tunnel with a circumference of $\mathbf{4 0 0}$ metres. The first ten 'public beamlines', whose commissioning has been brought forward to February 1997, will be available for use by researchers from universities and national research institutes not directly associated with RIKEN or JAERI from October 1997.

The beams will be used for a wide variety of studies, including research on protein crystallography, soft X-ray spectroscopy of solids, high-energy inelastic scattering, nuclear resonant scattering, structural analysis of extremely dense states of matter under high pressure, physicochemical analysis, soft X-ray photochemistry, crystal structure analysis, and structural studies of expanded fluids at high temperatures.

Stephen Barker 